\title{
En la búsqueda de más transparencia en la línea editorial
}

\author{
In search for more transparency in editorial line
}

Revista Argentina de Cardioangiología Intervencionista 2019;10(1):11-12. DOI: 10.30567/RACI/201901/0011-0012

Desde este número de la Revista hemos agregado en su versión web (www.revistacaci.org.ar) la declaración de posibles conflictos de intereses para cada uno de los que conformamos el Comité Editorial de la Revista Argentina de Cardioangiología Intervencionista (RACI) y que residimos en nuestro país: Editor en Jefe, Editores Asociados y Secretaría Científica.

Esto no significa que eventualmente cada uno de nosotros no pueda tener alguna relación con la industria farmacéutica y/o de dispositivos relacionados con nuestra especialidad. De hecho, alguno de nosotros la tuvo en el pasado, la tiene actualmente o la podría tener en el futuro, pero creo que es muy importante que los lectores conozcan estas relaciones, si las hubiese, claramente expuestas en una página con el nombre de cada uno de nosotros.

La relación de los editores de revistas médicas así como de aquellos responsables de confeccionar las guías de tratamiento, si bien es una cosa sospechada desde hace tiempo, fue claramente demostrada por artículos de investigación reportados, algunos recientemente ${ }^{1}$.

En un artículo publicado en el BMJ 2017, los autores ${ }^{1}$ analizan las relaciones de la industria con editores y Comité Editorial de 52 revistas de alto impacto de EE.UU. y seleccionaron entre 20 especialidades más relevantes: medicina interna, cardiología, ortopedia, endocrinología, obstetricia, oncología, cirugía, neurología, nefrología, reumatología, urología etc. Para demostrar la relación usaron el registro oficial de honorarios y gastos publicados en un registro publico (www.cms.gov/openpayments/) que existe en ese país para toda la industria farmacéutica y de dispositivos.

De estas 52 revistas incluyeron 713 editores, de los cuales más de la mitad tenía con la Industria fuertes lazos, entre ellos formar parte de compañías de dispositivos que usaron la revista de la que eran editores para publicar la mayoría de sus trabajos de investigación con el dispositivo de su propiedad. Las especialidades que mostraron más conflictos de intereses de sus editores fueron, en orden decreciente: 1) endocrinología, 2) cardiología, 3) gastroenterología, 4) reumatología y 5) urología. Estos autores también encontraron que en solo el $32 \%$ de las revistas los conflictos de intereses de sus editores fueron fácilmente identificables.

Teniendo en cuenta que solo se analizaron revistas científicas de alto impacto (bigh impact factor) -a quienes deseen más información sobre el tema los remito al artículo en cuestión ${ }^{1}-$, es importante que los potenciales conflictos de intereses sean entonces expresamente declarados por todos aquellos que tienen influencia a la hora de decidir la publicación de un reporte científico, que serían: los autores del trabajo, los revisores y los editores encargados del manejo del artículo una vez que el mismo fue remitido.

Estos conflictos de intereses también están presentes a la hora de escribir y/o modificar guías de tratamiento, como fue observado en estudios que analizaron este tipo de conflictos en un extenso panel de expertos en diabetes y cardiología en EE.UU. y Canadá, donde identificaron que más del 50\% tenía conflictos de intereses así como también aquel que tomaba decisiones más importantes al momento de escribir las guías ${ }^{2,3}$. Y esto fue más relevante cuando los investigadores provenían de organismos no gubernamentales.

Es decir, está claro que nuestras relaciones con la Industria nos acompañan a lo largo de toda nuestra carrera médica y abarcan, sin duda, distintas especialidades. Y probablemente cuanto mayor sea el nivel académico alcanzado en su profesión mayores los riesgos de esa relación dado el nivel referencial del médico.

Sin embargo, si estas relaciones están suficientemente declaradas y conocidas, su existencia no constituye ninguna limitante. Por ello nos parece muy importante que todos los autores que envían trabajos a nuestra revista también conozcan los potenciales conflictos, en caso de existir, que puedan tener cada uno de los editores de la revista $R A C I$ con determinados artículos o temas remitidos para consideración de ser publicados, a fin de que quienes puedan presentar potenciales biases se excusen en ser partícipes de la revisión y/o manejo editorial del trabajo.

Alfredo E. Rodríguez MD, PhD, FACC, FSCAI, IAGS Editor en Jefe Revista Argentina de Cardioangiología Intervencionista (RACI) arodriguez@centroceci.com.ar 


\section{BIBLIOGRAFÍA}

1. Liu JJ, Bell CM, Matelski JJ, Detsky A, Cram P. Payments by US pharmaceutical and medical device manufacturers to US medical journal editors: retrospective observational study. BMJ 2017;359:j4619http://dx.doi. org/10.1136/bmj.j4619

2. Neuman J, Korestein D, Ross JS, Keyhani JN. Prevalence of financial conflicts of interest among panel members producing clinical practice guidelines in Canada and United States: cross sectional study. BMJ 2011 Oct 11;343:d5621.doi:10.1136/bmj.d5621.

3. Mendelson TB, Meltzer M, Campbell EG, Caplan AL, Kirkpatrick JN. Conflicts of interest in cardiovascular clinical practice guidelines. Arch Intern Med 2011 Mar 28;171(6):577-84.doi:10.1001/archinternmed.2011.96. 